Paper

\title{
Multi-imaging hologram for physics education 物理教育のためのホログラフィック多重記録実験
}

Takehisa SHIBUYA, Toshinori KIMURA, and Moriaki WAKAKI

Department of Optical Imaging and Science \& Technology, Tokai University, 1117 Kitakaname, Hiratsuka, Kanagawa, 259-1292 Japan

TEL:x81-463-58-1211(EXT:4434) FAX: x81-463-59-2594 e-mail: shibuya@keyaki.cc.u-tokai.ac.jp

Hidetoshi KATSUMA

School of Science, Tama Art Univ., 1723 Yarimizu, Hachioji, Tokyo 192-0394 Japan

TEL: $x 81-426-79-5628$

( Received 4, July 2007 Accepted 25, August 2007 )

Fundamental experiments of multiple image recording were carried out for university students to understand the basic concept of the 3D image storage. We performed holographic image recording experiments using simple two beam interference. Multiple images recording of 2D and $3 \mathrm{D}$ were successfully performed.

Keywords : Hologram, Physics education, Multi-imaging hologram

\section{INTRODUCTION}

ガボアによってホログラフィーが発明されてから 50 年経過

し1、今ではホログラムは3次元画像を記録する方法として広 く知られている。 ${ }^{2 \sim 4}$ ホログラムはカラーフィルターや偏光メガ ネなどを用いることなしに3次元イメージを得ることが出来る。 ディスクホログラムは被写体の上方から照明した光で照らし 出された情報を記録できるので、円盤の上に記録したホログ ラムを回転させると、ディスク上に見えている被写体も回転し て見ることが出来る。一般にホログラムは静止像の場合が多 いが、動きのある物を記録した物もある。例えばマルチプレッ クスホログラムの場合、動きがある被写体をカメラなどで撮り、 その像を乾板に細い短冊状にホログラムとして記録する。繋 げたホログラムを動かしながら参照光を当てると、カメラで撮 影した状態を再現することが出来る。

我々はこれまでホログラムを通した物理教育に関していく つかの提案をしてきた。 ${ }^{5,6}$ 本論文では、1枚の乾板に多数の ホログラムを縮小記録、再生する事を通じて動画ホログラム の基本的概念を理解させるための、学生向けマルチイメー ジホログラムの基礎実験を行った。

\section{EXPERIMENTAL SETUP}

学生にホログラフィック記録の基本原理を理解させるため に2光束干渉法を採用した。ディスプレーとしてのホログラム は3次元像を記録するが、ホログラフィック記録実験では、2 次元データを記録する。多くのディスプレーホログラムの場 合、被写体をホログラム乾板に等倍 $(1: 1)$ で記録している。 情報記録の観点からは記録領域は小さければ小さいほど多 くのデータが記録できる。実際のデータ記録の場合には $\phi$ $200 \mu \mathrm{m}$ 程度までビームを絞る必要があるが、この実験では 記録領域は $\phi 2 \mathrm{~mm}$ 程度とした。ホログラフィツク記録の場合 では、記録位置がずれていれば、再生像も違うところに形成 されるため多重記録が可能である。これは円周方向および 半径方向の両方において可能である。本実験では円周方向 で記録領域を半分重ねた多重露光の実験を行った。

\section{OPTICAL SETUP}

記録のための光学系を Fig.1(a)〜 (b)に示す。Fig.1(a)は透 過型の等倍記録、(b)は縮小透過型の記録光学系である。

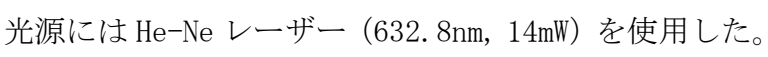



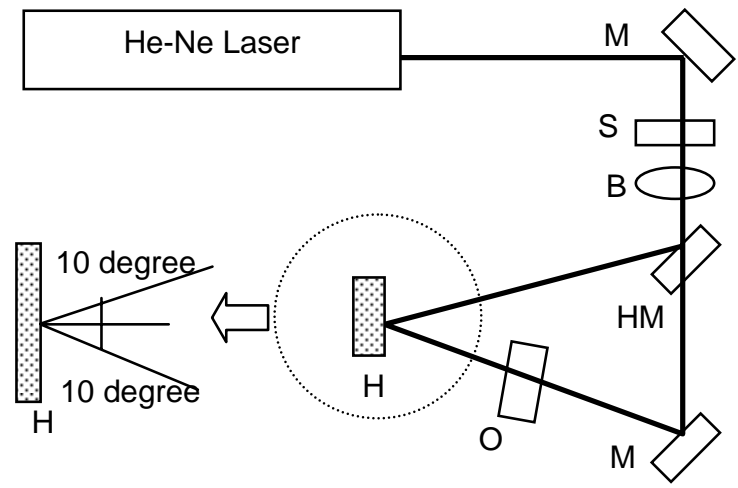

(a)

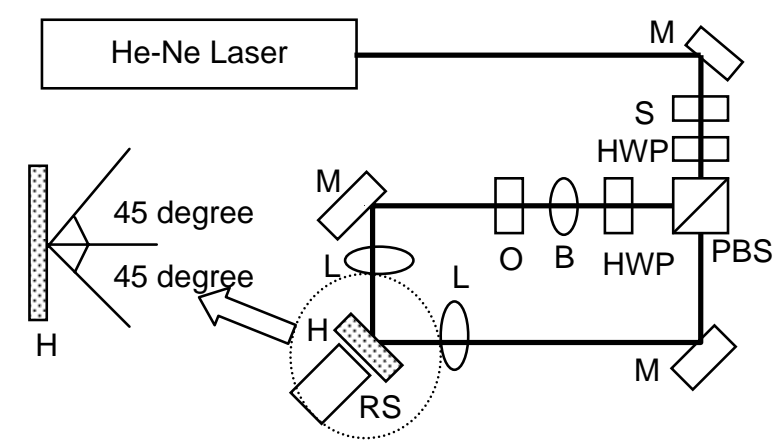

(b)

Fig. 1. Optical configurations for holographic image recording experiments. (a) a unit magnification, (b) a reduction magnification. In the figures, each notation means as follows; B: Beam expander, H; Hologram plate, HM: Half Mirror, HWP; Half Wave Plate, L: Lens, M; Mirror, O: Object, PBS: Polarization beam splitter, RS; Rotary Stage, and S; Shutter.

光源から出た光は偏光ビームスプリッターにより 2 光束に 分割させられる。一方の光は物体光、もう一方の光は参照光 に使用する。記録に使用した 2 次元データを Fig. 2 に示寸。 透過型光学系であるため、2 次元デー夕は透過物体でなけ ればならないため、視覚的に判るようにアルファベットを $\mathrm{OHP}$ 用シートに印刷したものを用いた。被写体の大きさは $20 \times 20$ mmである。複数の情報を記録するには作成した記録デー 夕を交換しなければならないが、その代わりに液晶等電子表 示装置を用いることで代用することも可能である。

記録材料としては大面積を有する書き換え可能な記録材 料が無いため、一般的なホログラム乾板 PFG-01 を使用し た。この乾板の最適路光量は $175 \mu \mathrm{J} / \mathrm{cm}^{2}$ 、現像処理は MA
現像液で 4 分、EDTA 漂白液で 2 分、液温は $18 \sim 19^{\circ} \mathrm{C} と し$ た。

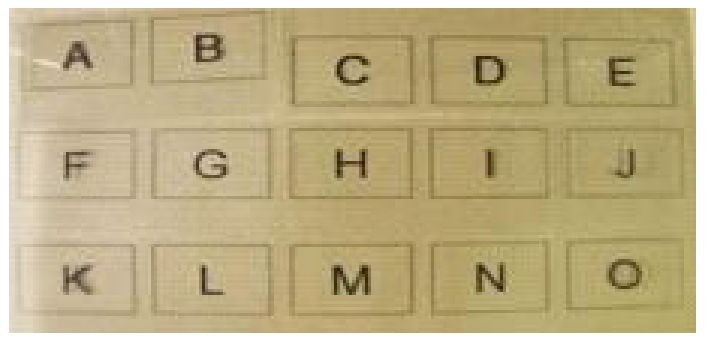

(a)

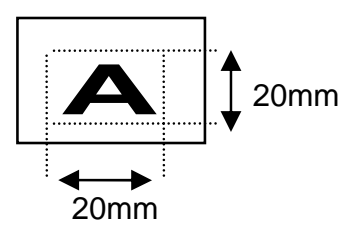

(b)

Fig. 2. Alphabet characters printed on an OHP film for holographic recording experiments (a) and size of character (b).

\section{RESULTS}

\section{IV-A. Unit magnification (1:1) recording experiments}

2次元記録データと記録領域の大きさが 1:1 の等倍記録 実験を行った。ホログラムの撮影条件を Table 1 に示す。記 録領域が重ならないように、一度露光した後、ホログラム乾 板を横方向にずらしてセットした。ホログラム乾板をセットした 後、除振台上にある乾板ホルダーや光学素子を止めている スタンド、ポール等の摇れを取り除くための時間(安定時間) をおいた後、露光した。

記録されたホログラムおよびレーザー光による再生像を Fig.3 (a)，(b)に示す。OHP 上に作成した2次元データの黒文 字の部分からは物体光が透過しないので、ホログラム乾板上 には元の2次元記録データの黒の部分が抜けた像が記録さ れた(Fig.3 (a))。参照光を当てると画像デー夕は再生された が、写真と同じように文字の部分が黒く抜けているのが確認 
された。

等倍記録実験で記録領域を半分ずつ重ねた場合の結果 を Fig.4 (a), (b)に示す。ホログラムの視域を狭くしなかったの で、再生光によって、両隣の像が同時に再生され多重に見 えているのが分かる(Fig.4 (b))。

Table 1 Recording condition at unit magnification.

\begin{tabular}{|l|l|}
\hline Object beam intensity & $57 \mu \mathrm{W}$ \\
\hline Reference beam intensity & $119 \mu \mathrm{W}$ \\
\hline Exposure time & $1 \mathrm{sec}$ \\
\hline Settling time & $1 \mathrm{~min}$ \\
\hline
\end{tabular}

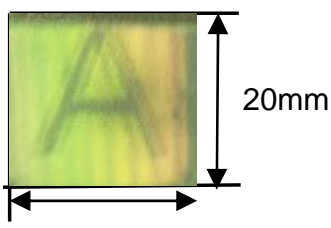

$20 \mathrm{~mm}$

(a)

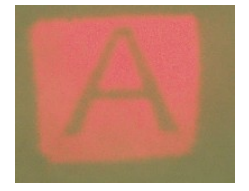

(b)
Fig. 3. Recording experiment at a unit magnification. (a) hologram, (b) reconstruction image

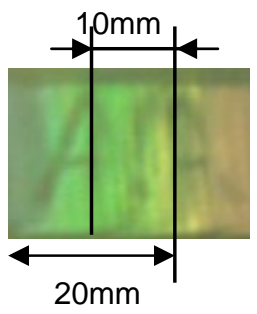

(a)

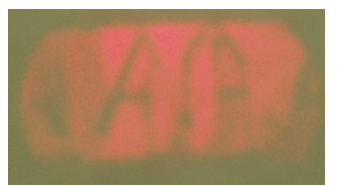

(b)
Fig. 4. Multiple recording experiment at a unit magnification. (a) hologram (b) reconstructied image

\section{IV-B. Reduction magnification (10:1) recording experiments}

レンズを使用した縮小透過型光学系を用いて記録実験を 行った。光学系を Fig. 1(b)に示す。記録領域は直径 $2 \mathrm{~mm}$ 程 度、撮影条件をTable 2 に示す。記録されたホログラムを Fig. 5 (a)に、直径 $2 \mathrm{~mm}$ のホログラム 1 つにレーザー光を入射した 場合の再生像を Fig. 5 (b)に示す。記録領域が小さいのでホ
ログラム乾板に記録された被写体のイメージは肉眼で確認 することは出来なかったが、再生像を確認することが出来た。 記録領域が直径 $2 \mathrm{~mm}$ 程度でもホログラムの記録・再生が可 能であることが判った。

Table 2 Recording condition at reduction magnification.

\begin{tabular}{|l|l|}
\hline Object beam intensity & $70 \mu \mathrm{W}$ \\
\hline Reference beam intensity & $140 \mu \mathrm{W}$ \\
\hline Exposure time & $0.8 \mathrm{sec}$ \\
\hline Settling time & $1 \mathrm{~min}$ \\
\hline
\end{tabular}

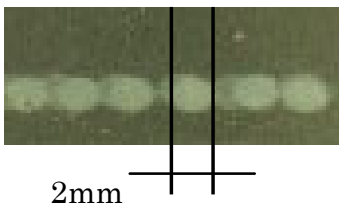

(a)

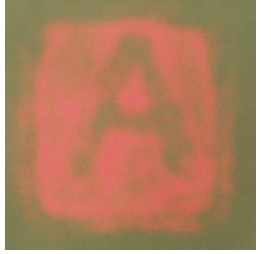

(b)
Fig. 5. Recording experiment at a reduction magnification. (a)hologram, (b) reconstructed image

IV-C. Fundamental experiments of multiimaging hologram

ホログラムデータの記録を行うに際して、ホログラムフィル ム上に直線的に記録する方法とホログラム乾板上に CD や DVD のように円周方向に記録する方法がある。本研究では ディスクホログラムをイメージしてホログラム乾板をステッピン グモータ駆動の回転ステージに取り付けるとともにレンズによ る縮小を行い、円周方向にデータを記録する実験を行った。 記録領域は直径 $2 \mathrm{~mm}$ 、ホログラム乾板の半径 $50 \mathrm{~mm}$ の円周 上に、1周で 102 個のホログラム像を記録した。安定時間が 短すぎると干渉縞が動くため再生像のコントラストが落ちてし まう。特に安定時間を 10 秒以下にすると除振出来ず像が記 録されなかった。記録領域が小さいことから、これまでの実験 と同じように安定時間を1分間として、ホログラムを撮影した。 作製したホログラムを Fig. 6 (a) に、直径 $2 \mathrm{~mm}$ のホログラム 1 つにレーザー光を入射した場合の再生像を Fig. 6(b) に示 
す。回転ステージにホログラム乾板を取り付けた光学系を使 用しても十分明るい再生像が得られている。

マルチイメージホログラム(多重記録)のための光学系を Fig. 7 に示す。被写体にはサイコロを用いた。使用したサイコ ロは反射物体であるため等倍の反射型光学系を用いた。参 照光の直径は $30 \mathrm{~mm}$ である。ホログラム乾板と被写体はそれ ぞれステッピングモータ駆動の回転ステージに取り付けられ ている。一度露光した後、被写体とホログラム乾板ともに同じ 角度だけ回転させる。ステージが停止した後、10秒間の安 定時間をとり、再び露光する。この操作を被写体が一周する まで繰り返す。回転角度は被写体の一周を 20 コマに分けて 作製する時には 18 度、25コマの場合には 14.4 度である。ホ ログラムの記録領域はいずれの場合でも重なっている。実験 装置を Fig.8 に, 撮影条件を Table3 に示す。

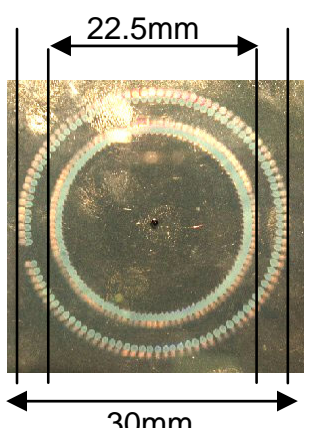

(a)

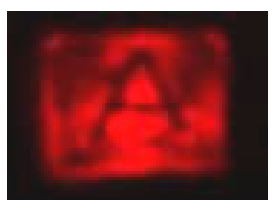

(b)
Fig. 6. Circumferential recording experiment (a) hologram, (b) reconstructed image

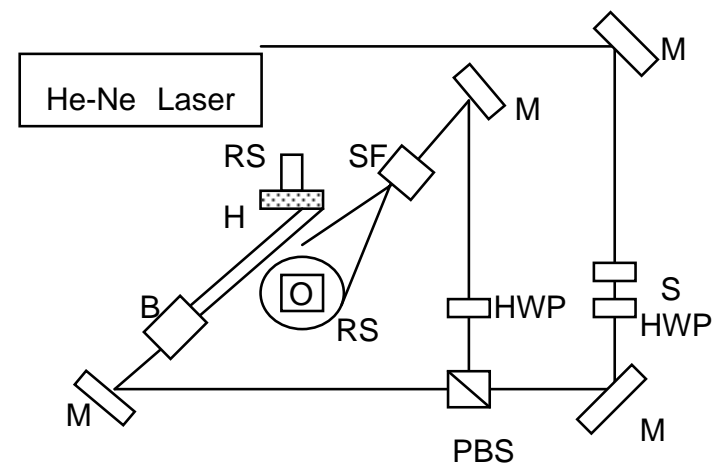

Fig. 7. Holographic animation recording experiment. In the figures, each notation means as follows; B: Beam expander, H: Hologram plate, HWP: Half Wave Plate, M: mirror, O: Object, PBS: Polarization Beam Splitter, RS: Rotary Stage, S: Shutter, and SF: Spatial Filter.

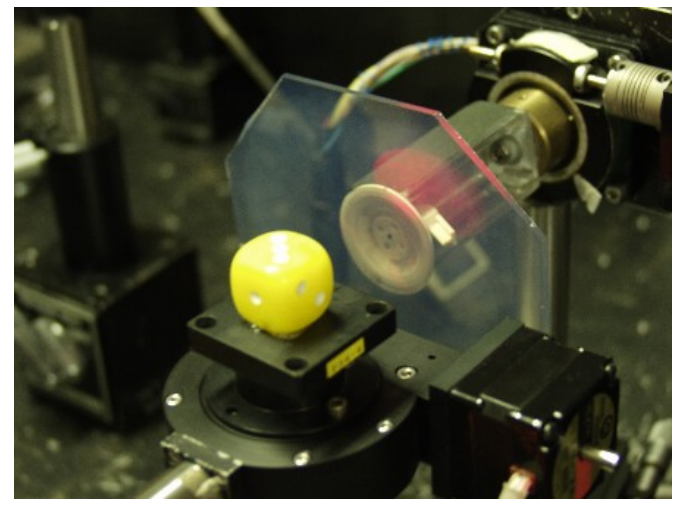

Fig. 8. Object (a die) and hologram plate on the rotary stage.

Table 3 Recording condition for multi-imaging recording.

\begin{tabular}{|l|l|}
\hline Object beam intensity & $56 \mu \mathrm{W}$ \\
\hline Reference beam intensity & $108 \mu \mathrm{W}$ \\
\hline Exposure time per point & $2.5 \mathrm{~s}$ \\
\hline Settling time & $10 \mathrm{sec}$ \\
\hline Radii of the circles & $35 \mathrm{~mm}$ \\
\hline Recorded times within a circle & 20,25 times \\
\hline Recorded area per point & $\phi 25 \mathrm{~mm}$ \\
\hline
\end{tabular}

現像、漂白処理を行ったホログラム乾板を撮影の時と同じ 回転ステージに取り付け、再生光をホログラム乾板に照射す ることで再生像を得ることが出来た。一周を 20 コマ、25 コマ に分割して撮影したホログラムの再生像を Fig. 9(a)，(b)にそ れぞれ示す。ホログラムは回転させず固定した状態である。

一周 20 コマに分割して撮影した場合，ほぼ1コマずつの像 が再生できたが、一周 25 コマの場合には、前後のサイコロ 像が重なって見えている。これはホログラムの視域に関係し ており、一コマのホログラム再生像が重ならないようにするに は, 記録領域を狭くする、被写体とホログラム乾板との距離 を離すなどする必要がある。

次に再生光を照射した状態でホログラムを回転させた場 合、25 コマに分割したホログラムの方が被写体の回転が滑ら かに観測された。1 周の分割数を多くするとより滑らかに見え るが、記録領域の重なる範囲が広くなり、前後の再生像が重 なって観察されてしまう。ホログラムを回転させて滑らかに再 
生像を観測するためには、参照光の大きさを小さくすること、 レンズ等を入れて記録領域を狭くするなどの工夫が必要で ある。

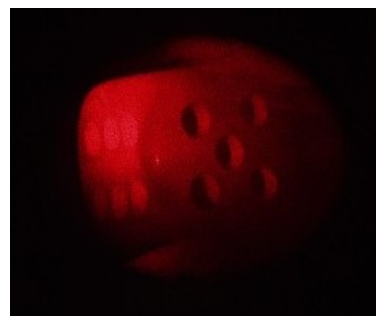

(a)

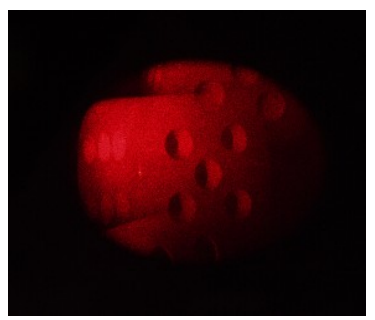

(b)
Fig. 9. Reconstructed image of hologram. (a) 20 images recording, (b) 25 images recording.

\section{CONCLUSIONS}

2光束光学系によるホログラフィック多重記録の実験を行 った。簡単な装置でホログラフィック記録実験を行うことが確 認できた。透過物体を等倍記録した場合、作製したホログラ ム自身に透過像が見えたが、縮小記録した場合には確認す ることが出来なかった。再生光としてレーザー光を入射させ ると、どちらの場合でも再生像を確認することが出来た。

回転ステージにホログラム乾板を取り付けた、透過物体の 縮小記録・再生実験ならびに反射物体の等倍記録・再生実 験を行った。その結果、十分な明るさの再生像を得ることが できた。物体の回転(全周方向)を記録するなどホログラム乾 板への記録の多重度を上げた場合、視域の関係で再生像 が重なると言う問題点が明らかになった。ホログラム乾
板への撮影の多重度を上げれば記憶量を増やすことが 出来るが、安定時間のためホログラム作製に要する時間が 長くなってしまう。そのため光源に高出力短パルスレーザー を使用すれことによって安定時間をとる必要がなくなり、作製 時間の撮影時間が短縮される。

この実験システムを用いることでホログラフィック多重記録 の基本的概念を学ぶとともに、比較的容易にディスクホログ ラムを作成する事が出来るようになった。

\section{REFERENCES}

1. D. Gabor, Nature, 161, p.777, 1948.

${ }^{2 .}$ Charles M. Vest, Holography interferometry, John Wiley \& Son, New York, 1979.

${ }^{3 .}$ F. Unterseher, J. Hansen, and B.Schlesinger, Holography Handbook, Ross Books, Berkley, 1987.

4.T.H. Jeong, "Large-scale holographic display system,” Proc. of SPIE, 4296, pp.38-46, 2001.

${ }^{5 .}$ H. Katsuma, T. Kimura, T. Shibuya, and M. Wakaki, "Holography for physics education in universities and colleges, ”Proc. of SPIE 5243, pp.89-95, 2003.

6. T. Shibuya, H. Katsuma, M. Wakaki, and H. Yokota, "Educational application and development of easy holography system using a laser pointer, ”Jpn. J. Appl. Phys. Education. (in Japanese), 24, pp.85-88, 2000. 
